\title{
Shock Synthesis of $\mathrm{Gd}_{2} \mathrm{Zr}_{2} \mathrm{O}_{7}$
}

\author{
Toshimori Sekine ${ }^{1_{*}}$, Qiang Zhou ${ }^{2}$, Pengwan Chen ${ }^{2}$, Zhen $\operatorname{Tan}^{2}$, Haotian Ran $^{2}$, \\ and Jianjun $\mathrm{Liu}^{3}$ \\ ${ }^{1}$ Center for High Pressure Science \& Technology Advanced Research, P.R. China \\ ${ }^{2}$ Beijing Institute of Technology, P.R. China \\ ${ }^{3}$ Beijing University of Chemical Technology, P.R. China \\ * toshimori.sekine@hpstar.ac.cn
}

Keywords: Shock Synthesis, Pyrochlore, Fluorite, Weberite, Solid Reactions, $\mathrm{Gd}_{2} \mathrm{Zr}_{2} \mathrm{O}_{7}$

\begin{abstract}
We dealt with shock compression on a composition of $\mathrm{Gd}_{2} \mathrm{Zr}_{2} \mathrm{O}_{7}$ by explosive-driven flyer impact methods, because $\mathrm{Gd}_{2} \mathrm{Zr}_{2} \mathrm{O}_{7}$ with $\mathrm{r}_{\mathrm{Gd}} / \mathrm{r}_{\mathrm{Zr}}$ ration of 1.46 lies at the structural boundary between ordered pyrochlore and defect fluorite structures. The results indicate recovered products depend on shock conditions that we need to specify by further study.
\end{abstract}

\section{Introduction}

Shock compression process provides unique environments for materials synthesis due to not only the realized high pressure and high temperature but also the shock-enhanced kinetics and fast quenching [1]. The process is a time-limited reaction and favors martensitic phase transformation in general. There are many trials to use shock compression techniques for investigation of solid state reactions [2]. The most typical one has been known historically as diamond synthesis, and the process has been developed to optimize the yield of products. Here we report a progress of shock synthesis of oxide compounds using explosive-driven plate impacts.

Rare earth pyrochlore compounds of $\mathrm{A}_{2} \mathrm{~B}_{2} \mathrm{O}_{7}$, where $\mathrm{A}$ is a rare earth element and $\mathrm{B}$ is a tetravalent cation such as $\mathrm{Zr}^{4+}$ and $\mathrm{Ti}^{4+}$, exhibit several interesting properties for physical, chemical and industrial applications. The pyrochlore structure is known to form if the cation radii ratio $\left(\mathrm{r}_{\mathrm{A}} / \mathrm{r}_{\mathrm{B}}\right)$ lies in the range 1.46-1.80. However, the fluorite structure is favored with $\mathrm{r}_{\mathrm{A}} / \mathrm{r}_{\mathrm{B}}$ below 1.46. The cation radii ratio $\mathrm{r}_{\mathrm{A}} / \mathrm{r}_{\mathrm{B}}$ has an important effect on the high pressure structural stability. $\mathrm{Gd}_{2} \mathrm{Zr}_{2} \mathrm{O}_{7}$ with $\mathrm{r}_{\mathrm{A}} / \mathrm{r}_{\mathrm{B}}$ ratio of 1.46 lies at the structural boundary between ordered pyrochlore and defect fluorite. Hence it is expected to show interesting structural behavior as a function of temperature and pressure. We tried to understand the effect of shock compression on $\mathrm{Gd}_{2} \mathrm{Zr}_{2} \mathrm{O}_{7}$. Among $\mathrm{A}_{2} \mathrm{~B}_{2} \mathrm{X}_{7}$ ( $\mathrm{X}$ is anion such as $\mathrm{O}$ and $\mathrm{F}$ ) compounds there are three discrete structures of pyroclore, fluorite, and weberite. Their structural relations are based on the fluorite structure $\left(\mathrm{AX}_{2}\right)$ where each anion is at the center of the cation tetrahedral $\left(\mathrm{A}_{4} \mathrm{X}\right)$ and the lattice is characterized by a lattice constant of $a=\sim 5 \AA$ with $\mathrm{Z}=1$. In pyrochlore structure, different $\mathrm{A}$ and $\mathrm{B}$ cations make $\mathrm{A}_{4} \mathrm{X}, \mathrm{B}_{4} \mathrm{X}$, and $\mathrm{A}_{2} \mathrm{~B}_{2} \mathrm{X}$, and the lattice is expanded double $(a=\sim 10 \AA$ ) and the number of $\mathrm{Z}=8$. Weberite consists of $\mathrm{A}_{3} \mathrm{BX}, \mathrm{AB}_{3} \mathrm{X}$, and $\mathrm{A}_{2} \mathrm{~B}_{2} \mathrm{X}$, with lattice constants of $\sqrt{2} a, 2 a$, and $\sqrt{ } 2 a$ and with $Z=4$. Therefore, pyrochlore and weberite have their corresponding superlattices in addition to the fluorite structure.

Shock compression technique has never been applied to solid-solid reactions in complicate chemical systems to our knowledge. We explore such chemical systems using shock compression techniques. 


\section{Experimental methods}

We dealt shock compression on two starting mixtures of a composition $\mathrm{Gd}_{2} \mathrm{Zr}_{2} \mathrm{O}_{7}$ (powdered mixture of $\mathrm{Gd}_{2} \mathrm{O}_{3}+2 \mathrm{ZrO}_{2}$ and the product heated in air at $900{ }^{\circ} \mathrm{C}$ for 2 hours), encapsulated in copper containers, by explosive-driven flyer impact methods [3]. A copper flyer with a diameter of $40 \mathrm{~mm}$ and a thickness of $2 \mathrm{~mm}$ is accelerated to a high velocity by the detonation of the main explosive charge of nitromethane (CH3NO2), initiated by a booster charge of 8701 explosive [3]. Peak shock pressure reflected within a sample is calculated by the impedance match method from the known impact velocity. The shock velocity (Us $\mathrm{km} / \mathrm{s}$ )- particle velocity (Up $\mathrm{km} / \mathrm{s}$ ) relation of copper [4] with density of $8.924 \mathrm{~g} / \mathrm{cm}^{3}$ ) is used as Us $=3.91+1.51 \mathrm{Up}$. The starting material preheated at $900{ }^{\circ} \mathrm{C}$ (sample I) was partially reacted to a fluorite structure with monoclinic $\mathrm{ZrO}_{2}$ according to the powder x-ray diffraction (XRD) analysis (Fig. $1 \mathrm{~A}, \mathrm{~B}$, and $\mathrm{C}$ ). Another starting material (sample II) was a mixture of $\mathrm{Gd}_{2} \mathrm{O}_{3}$ and monoclinic $\mathrm{ZrO}_{2}$ as the received powders.

The container after shot was cut open to remove the sample. The successfully recovered samples as well as the starting materials were investigated by powder x-ray diffraction methods to identify phases present in products. We carried out a series of recovery experiments as a function of impact velocity and porosity.

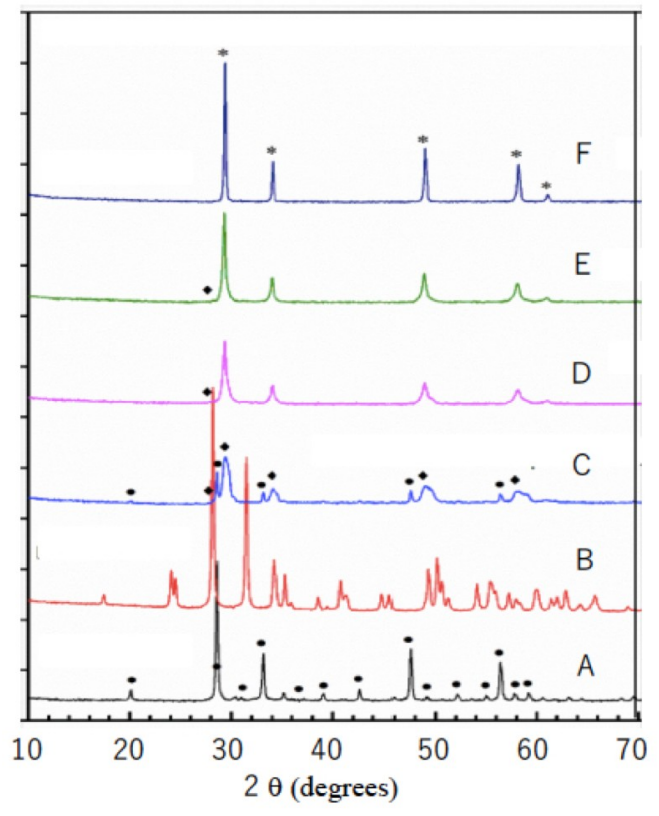

Fig. 1. XRD patterns using $\mathrm{Cu} K \alpha$ radiation for sample I.

(A) $\mathrm{Gd}_{2} \mathrm{O}_{3}$ after heated at $1000^{\circ} \mathrm{C}$ for 4 hours,

(B) $\mathrm{ZrO}_{2}$ after heated at $800^{\circ} \mathrm{C}$ for 4 hours,

(C) Product from a mixture of (A) and 2 (B) after heated at $900^{\circ} \mathrm{C}$ for 2 hours,

(D) Recovered sample I with porosity of $48 \%$ at $43.5 \mathrm{GPa}$, (E) Recovered sample I with porosity of $40 \%$ at $60.0 \mathrm{GPa}$, and (F) Recovered sample I with porosity of $54 \%$ at $84.9 \mathrm{GPa}$.

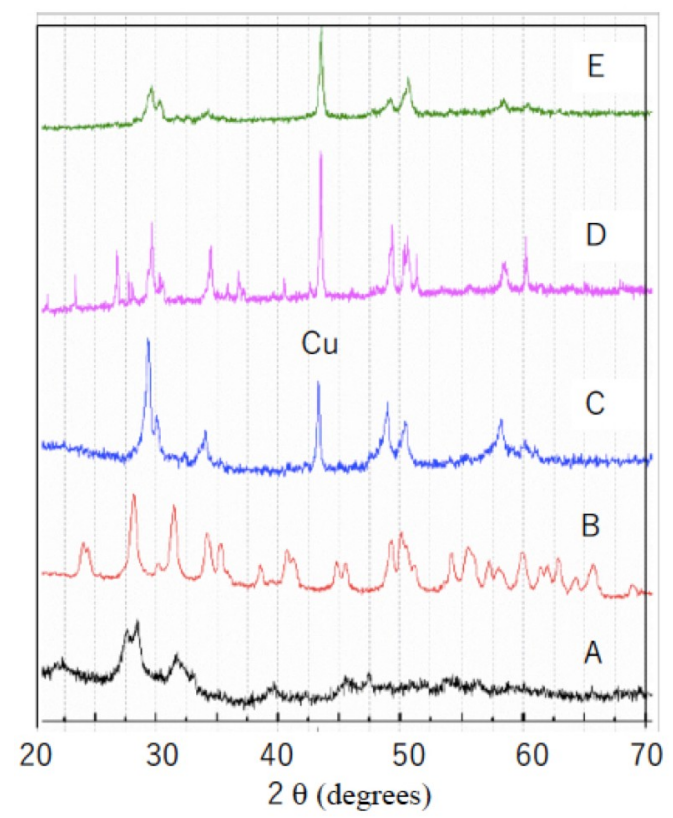

Fig. 2. XRD patterns using $\mathrm{Cu} K \alpha$ radiation for sample II.

(A) $\mathrm{Gd} 2 \mathrm{O} 3$ as received, (B) $\mathrm{ZrO} 2$ as received, (C) Recovered sample II with porosity of $50 \%$ at $60.0 \mathrm{GPa}$, (D) and (E) Recovered sample II with porosity of $30 \%$ at $84.9 \mathrm{GPa}$. Peak with $\mathrm{Cu}$ Indicates the highest peak for $\mathrm{Cu}$. 


\section{Results and discussion}

We have started a series of shock recovery experiments on various pyrocholre compounds that has not known yet, and explore novel compounds using shock compression. We report and discuss the results on two bulk compositions of $\mathrm{Gd}_{2} \mathrm{Zr}_{2} \mathrm{O}_{7}$. Impact velocities of $1.85 \mathrm{~km} / \mathrm{s}, 2 / 36$ $\mathrm{km} / \mathrm{s}$, and $3.06 \mathrm{~km} / \mathrm{s}$ of Cu flyers correspond to peak shock pressures of $43.5 \mathrm{GPa}, 60.0 \mathrm{GPa}$, and 84.9 GPa, respectively.

The XRD patterns of recovered samples indicate completely transformed to the fluorite structure with no additional peaks (Fig. 1 F) from sample I. The peaks sharpen with increasing shock pressure (Figs. $1 \mathrm{D}$ and E). The starting sample (Fig. $1 \mathrm{C}$ ) indicates peaks corresponding to a fluoride structure and $\mathrm{Gd}_{2} \mathrm{O}_{3}$ with no $\mathrm{ZrO}_{2}$. Although this result suggests that the fluorite is non-stoichiometric, the initial monoclinic $\mathrm{ZrO}_{2}$ may be transformed to cubic or tetragonal structure at shock-induced high temperatures. The maximum peaks for fluorite and tetragonal (or cubic) $\mathrm{ZrO}_{2}$ are close around 30 degree each other, and the difference between tetragonal and cubic $\mathrm{ZrO}_{2}$ is indistinguishable by XRD [5].

The products from the raw powder mixture (sample II), however, display two types of XRD patterns (Fig. 2). One consists of relatively broad peaks corresponding to a pyrochlore structure (Figs. $2 \mathrm{C}$ and $\mathrm{E}$ ) and the other indicate relatively sharp peaks of pyrochlore structure (Fig. D), although both contain significant amounts of copper powders from container and may contain small amount of tetragonal (or cubic) $\mathrm{ZrO}_{2}$. The copper contamination that we did not observed in sample I may suggest higher shock temperatures in sample II than sample I because the starting $\mathrm{Gd}_{2} \mathrm{O}_{3}$ powder was poorly crystalline (Fig. 2 A).

Then, the presence of a large amount of copper in the recovered sample II can be explained by high temperatures, although the porosity difference may affect the shock temperature. The formation of fluorite $\mathrm{Gd}_{2} \mathrm{Zr}_{2} \mathrm{O}_{7}$ suggests relatively high temperatures $\left(>1530^{\circ} \mathrm{C}\right)$ in hot press sintering [6]. If this is the case, our shock temperatures could be close to this. The effects of porosity of the initial powders pressed in the recovery container are not well controlled in the present study, and we need further study. However, high temperatures generated in powdered samples are found to promote solid reaction significantly. It is difficult to understand the shock pressure effect on the solid reaction due to a small difference between fluorite and pyrochlore structures at high pressures. Based on a detailed study of the lattice parameter of $\mathrm{Gd}_{2} \mathrm{Zr}_{2} \mathrm{O}_{7}$ with fluorite and pyrochlore structures at ambient condition [7], the pyrochlore has slightly larger volume than the fluorite and can be the low pressure. Therefore, we need to know shock conditions to understand the solid reactions. And also it is interesting to compare the static compression results on $\mathrm{Gd}_{2} \mathrm{Zr}_{2} \mathrm{O}_{7}$ at room temperature [8,9]. The results indicate back transformation from pyrochlore to defect-fluorite formed above $15 \mathrm{GPa}$ [8] and amorphization above 35 GPa due to distortion of cation [9].

\section{Summary}

Shock compressions of powders with a composition of $\mathrm{Gd}_{2} \mathrm{Zr}_{2} \mathrm{O}_{7}$ produced both defect fluorite and ordered pyrochlore structures detected by x-ray diffraction methods. The results need to be specified to understand the solid reactions.

\section{References}

[1] T. Sekine, Experimental methods of shock wave research for solids. In Hypervelocity Launchers (ISBN: 978-3-319-26016-7) Shock Wave Science and Technology Reference Library Vol. 10, F. Seifler and O. Igra (Eds), 55-76, Springer. 2016. https://doi.org/10.1007/978-3-31926018-1_3 
[2] S.S. Batsanov, Features of solid-phase transformations induced by shock compression. Rus. Chem. Rev. 75 (2006) 601-616. https://doi.org/10.1070/rc2006v075n07abeh003613

[3] Z. Tan , P. Chen, Q. Zhou, J. Liu, X. Mei, B. Wang, and N. Cui, Shock synthesis and characterization of titanium dioxide with $\alpha-\mathrm{PbO}_{2}$ structure J. Phys.: Condens. Matter 30 (2018) 264006. https://doi.org/10.1088/1361-648x/aac709

[4] S.P. Marsh, LASL Shock Hugoniot Data, University of California Press (1980).

[5] R. Srinivasa, R.J. De Angelis, G. Ice, and B.H. Davis, Identification of tetragonal and cubic structures of zirconia using synchrotron x-radiation source. J. Mat. Res., 6 (1991) 1287-1292. https://doi.org/10.1557/jmr.1991.1287

[6] U. Brykala, R. Diduszko, K. Jach, and J. Jagielski, Hot pressing of gadolinium zirconate pyrochlore. Ceramic Intern., 41(2015) 2015-2021. https://doi.org/10.1016/j.ceramint.2014.09.114

[7] Y.H. Leea, H.S. Sheub, J.P. Denga, and H.-C.I. Kao, Preparation and fluorite- pyrochlore phase transformation in Gd2Zr2O7. J. Alloy. Comp., 487 (2009) 595-598. https://doi.org/10.1016/j.jallcom.2009.08.021

[8] F.X. Zhang, J. Lian, U. Becker, R.C. Ewing, J. Hu, and S.K. Saxena, High-pressure structure changes in the $\mathrm{Gd}_{2} \mathrm{Zr}_{2} \mathrm{O}_{7}$ pyrochlore. Phys. Rev. B 76 (2007) 214104.

[9] N.R. Sanjay Kumar, N.V. Chandra Shekar, and P.Ch. Sahu, Pressure induced structural transformation of pyrochlore $\mathrm{Gd}_{2} \mathrm{Zr}_{2} \mathrm{O}_{7}$. Solid St. Comm., 147 (2008) 357-359.

https://doi.org/10.1016/j.ssc.2008.06.028 